\title{
A PAIXÃO SEGUNDO A. W. - notas sobre 0 ritual da serpente e as pathosformeln no pensamento de Aby Warburg ${ }^{1}$
}

\author{
Gabriela Reinaldo
}

\section{Resumo}

Em 1905, Aby Warburg formulou o que chamaria de Pathosformeln - neologismo criado por ele em seu estudo sobre Albrecht Dürer, mas que já aparecia de forma rudimentar em seus primeiros escritos. As Pathosformeln dizem respeito às forças psíquicas presentes na memória coletiva em formas espectrais, imagens dotadas de intensa energia primitiva. Se a história do pensamento no Ocidente concorre para a expulsão da paixão do domínio da lógica e da ciência a paixão atrapalha e embota 0 que se pretende lúcido e positivo -, o legado e a vida de A. W. são testemunhos dos inegáveis efeitos das paixões para as descobertas científicas. Antes, contudo, de sofisticar a tese que redimensionaria tudo o que já havia sido dito sobre 0 Renascimento, experiências de cunho pessoal - como sua internação em um asilo mental e 0 contato com indígenas do oeste americano - contribuíram para os seus insights sobre a arte florentina.

\section{Palavras-Chave}

Pathosformeln. Imagem. Ritual. Arte. Ciência.
Gabriela Reinaldo I gabriela.reinaldo@gmail.com Doutora em Comunicação e Semiótica pela Pontifícia Universidade Católica de São Paulo (PUC/SP), Brasil, Gabriela Reinaldo é professora e pesquisadora do Instituto de Cultura e Arte da Universidade Federal do Ceará (UFC), Brasil. Realizou estágio pós-doutoral no Departamento de História da Arte da Universidade de Cambridge, Inglaterra, e durante o período de um ano (agosto de 2013 a agosto de 2014 como bolsista pós-doutorado Sênior da Capes) fez cursos no Instituto Warburg, ligado à Universidade de Londres, além de pesquisas na biblioteca e arquivos do Instituto.
Treze anos após On the Origin of Species, Charles Darwin publica The Expression of the Emotions in Man and Animals (1872), sobre os aspectos geneticamente determinados do comportamento. Darwin já havia feito considerações a respeito do tema quando ele mesmo procura aconselhamento médico para distúrbios mentais que 0 acometiam nos anos 1830. Em seus cadernos pessoais de anotação, 0 fundador da teoria da seleção natural elucubrava em notas assistemáticas - muitas delas geradas a partir de conversas com seu próprio pai, que, como médico, dedicava especial interesse à área da psiquiatria sobre a possível interação de fatores hereditários nos aspectos mentais e comportamentais de humanos $\mathrm{e}$ animais. Em The Expression of the Emotions in Man and Animals, lê-se:

Reflex actions - Reflex actions, in the strict sense of the term, are due to the excitement of a peripheral nerve, which transmits its influence to certain nerve-cells, and these in their turn excite certain muscles or glands into action; and all this may take place without any sensation or consciousness on our part, though often thus accompanied. (...) As good an instance as can be given is the often-quoted one of a decapitated frog, which cannot of course feel, and cannot consciously perform, any movement. Yet if a drop of 
acid be placed on the lower surface of the thigh of a frog in this state, it will rub off the drop with the upper surface of the foot of the same leg. If this foot be cut off, it cannot thus act ${ }^{2}$.

A atroz convulsão da rã mutilada é citada na carta que Aby Warburg endereça a Friedrich (Fritz) Saxl, no dia 26 de abril de 1923. A carta, entretanto, não tem a intenção de discutir o tema nem faz qualquer alusão ao nome de Charles Darwin ${ }^{3}$. Curta (quase um bilhete) e bastante objetiva, nela Warburg pede expressamente a Saxl, que cuidou do Warburg Institute quando ele passou por um longo período de internação devido a problemas psiquiátricos, que não permitisse, em nenhuma hipótese, que os manuscritos da conferência que ele proferira no dia 21 de abril de 1923 viessem a público sem sua autorização. Mas o que se esconde neste pedido, para além do pragmatismo da demanda - A. W. não deseja que os manuscritos sejam publicados sem que ele possa se aprofundar no tema -, é revelador de sua personalidade e método de trabalho.

A imagem do animal em sofrimento no bilhete é uma metáfora de sua própria condição e de seus escritos.
A rã decapitada, como Warburg se refere aos papéis dessa conferência, poderia ser mostrada apenas a Mary Warburg (a quem ele se refere como "minha querida esposa"), ao Dr. Embden, ao seu irmão Max e ao Prof. Ernst Cassirer. 0 episódio toca em questões importantes para Warburg. 0 cuidado com uma produção que ele não julgava acabada - Warburg dizia que a conferência era informe e mal fundada no plano filológico, carente de maior aprofundamento para conferir credibilidade aos seus pensamentos - revela um pesquisador obsessivo com 0 apuro dos fatos e com a sistematização do pensamento. Mas, acima de tudo, alguém sensível ao sofrimento (pathos) e aos movimentos (que no caso da rã esfacelada são involuntários, instintivos e reflexivos). A estes, retornaremos.

\section{Ebreo di sangue, amburghese di cuore, d'anima fiorentino ${ }^{4}-$ as faces de Aby Warburg}

Aby Warburg, nascido em 1866 na cidade de Hamburgo, na Alemanha, é o filho mais velho de sete de uma família de banqueiros bem-sucedidos

Trabalho apresentado no GT Imagem e Imaginários midiáticos, Compós. Brasília, 2015.

0 original, de 1872, pode ser acessado no seguinte site: http://darwin-online.org.uk/contents.html\#books. Em português: "ações reflexas, no senso estrito do termo, se devem à estimulação de um nervo periférico que transmite seu efeito a certas células nervosas, que por sua vez estimulam certos músculos ou glândulas. Tudo isso pode acontecer sem nenhuma sensação ou consciência de nossa parte, embora muitas vezes elas estejam presentes (...) Um dos melhores e mais conhecidos exemplos é o da rã decapitada, que evidentemente não pode sentir e não pode conscientemente desempenhar nenhum movimento. No entanto, se uma gota de ácido for pingada sobre a superfície inferior da coxa de uma rã neste estado, ela vai esfregar essa gota com a superfície superior do pé da mesma perna. Se este pé for cortado, ele não pode agir".

A hipótese de que A. W. se refira a Darwin em seu bilhete é levantada pelo editor francês da obra Le Rituel du Serpent - art et anthropologie. Também E. Gombrich, em sua biografia sobre Warburg, comenta a respeito da importância de Darwin para o seu pensamento, tema que Georges Didi-Huberman retoma em L'image survivante - histoire de l'art et temps des fantômes selon Aby Warburg. Segundo Gombrich, quando A.W. lê The expression of the emotions, ele anota em seu diário que, finalmente, encontrou um livro que 0 ajuda a refletir sobre as questões de seu interesse - referindo-se especificamente nesta nota à tarefa de analisar 0 aumento da expressão facial em Masolino e Masaccio. As obras citadas nesta nota constam nas nossas referências. 
do século XIX (e ainda hoje em atividade no ramo internacional de finanças), que, aos treze anos, firmou um pacto com seu irmão Max abrindo mão do direito ao comando do banco da família que lhe cabia pela primogenitura. Em troca, Max teria que lhe prover o suporte financeiro necessário para que Aby pudesse comprar os livros que desejasse ao longo de toda a sua vida. Vale a pena ler o depoimento de Max, cinquenta anos depois, em 5 de dezembro de 1929:

Quando ele tinha treze anos, Aby me ofereceu o seu direito de primogenitura. Ele, como mais velho, estava destinado a ingressar na empresa. Eu estava então apenas com doze anos, muito imaturo para refletir, concordei em adquirir o seu direito de primogenitura. Contudo, 0 que ele pedia não era uma sopa de lentilhas, mas uma promessa de que eu compraria para ele todos os livros que ele desejasse. Depois de uma breve pausa para refletir, eu consenti (...) então, sem suspeitar, o que eu dei para ele - eu devo hoje admitir - foi um grande cheque em branco. (GOMBRICH, 1970: 22).

Não vou repetir informações biográficas que 0 leitor, certamente, já tem conhecimento ou que pode facilmente encontrar em outros autores, fontes mais autorizadas. Sem querer forçar soluções de causalidade entre a vida e a obra de Warburg (uma vez que não existe um vivido que, objetivamente, possa servir de explicação para a constituição

da nossa personalidade e para o modo como interpretamos como o mundo chega até nós), a minha intenção é tão-somente sublinhar alguns aspectos da biografia de A. W. em que podem ser lidos elementos matriciais da formação de um olhar que revolucionou o estudo da arte e das imagens. Especialmente, no que se refere às suas experiências com a imagem e com o sofrimento. Sofrimento que, no seu caso, está ligado a um estado de adoecimento do corpo e da mente. Desconforto físico e psíquico que provoca alterações na sua percepção das imagens do mundo, embaralhando seus significados com outras que fazem parte de um rico depósito de imagens internas 5 .

\section{Em Aby Warburg - an intelectual biography ${ }^{6}$,} Ernst Gombrich (1970: 7) diz que os que 0 conheceram relatam que ele tinha um olhar intenso e uma melancolia profunda, a qual aludia aos terrores da doença mental que 0 acometera, mas também alguém que adorava anedotas.

Quando perguntado sobre como ele se definiria, Aby respondia: "um homem pequeno com um bigode preto e que, às vezes, conta histórias no dialeto local, 1 metro e 59 de altura".

Refiro-me ao conceito de imagens endógenas, de Hans Belting (2007).

Mesmo sem tê-lo conhecido pessoalmente, E. Gombrich escreveu a mais completa biografia que se conhece de A. W.. Quando Gombrich chega ao Instituto Warburg, que, na época, se mudara recentemente para Londres, já fazia sete anos desde a morte de seu biografado. Seu trabalho consistia em lidar com os escritos e com as fotografias de Warburg, o que não era tarefa fácil, devido à letra do seu autor e à quantidade de anotações fragmentadas - segundo Gombrich (1970; 1991), Warburg era muito apegado aos seus rascunhos e não jogava fora nenhum papel, não descartava qualquer anotação. Quando percebe que os papéis traziam dados muito fragmentários, Gombrich começa a redigir comentários explicativos na intenção de que sua tarefa pudesse compor o segundo volume da biografia de Warburg. Esta, à época, já estava sendo elaborada por Gertrud Bing, assistente de A. W., que havia se encarregado da tarefa iniciada por Fritz Saxl, que começou a escrever usando informações contidas em algumas correspondências e diários pessoais de Warburg, mas que abandonou a empreitada antes de terminá-la. Imaginava-se que Gertrud escreveria sobre a vida de A. W. e que Gombrich se encarregaria de um volume à parte com suas ideias, baseadas no que diziam suas obras e anotações. Com a morte de Gertrud, Gombrich teve que combinar as duas tarefas. 
Aos seis anos, foi acometido por uma febre tifoide. 0 efeito das febres potencializa a dramaticidade das imagens de um livro de Honoré de Balzac que havia em sua biblioteca. Em seus delírios, Aby era atormentado pelas ilustrações grotescas de Petites misères de la vie conjugale, as quais são descritas em termos de um inquietante satanismo, especialmente em relação à escala das personagens. Como podemos observar na imagem a seguir, ilustração de Bertall, 0 casal se debate histericamente como um par de títeres nas mãos de uma gigantesca figura mefistotélica.

\section{Em Limage survivante - histoire de l'art et} temps des fantômes selon Aby Warburg, Georges Didi-Huberman (2002: 424), que vê elementos surrealistas no virulento rebu ilustrado por
Bertall, transcreve uma nota rascunhada por A. W., de 1923, sobre sua experiência com essa imagem:

\begin{abstract}
(eu gostaria de observar aqui que nenhum livro teve uma influência tão ficcional e subversiva na minha juventude quanto Les petites misères de la vie conjugale de Balzac, com as ilustrações francesas [de Bertall]. Nessas ilustrações se encontram os satanismos [parte apagada], estranhezas por exemplo no [ilegível] em imagens que eu ainda vi antes de cair doente de tifo em 1870 e que tiveram um papel curiosamente demoníaco nos meus delírios febris).
\end{abstract}

Esse tipo de experiência seria estudado posteriormente por Warburg, quando, apoiado nas teses de Tito Vignoli, analisa os reflexos fóbicos. 0 que não é compreendido e provoca uma excitação perturbadora, faz com que a mente crie, como contrapartida ao impenetrável, uma

Figura 1: llustração de Bertall para Les petites misères de la vie conjugale, de Balzac

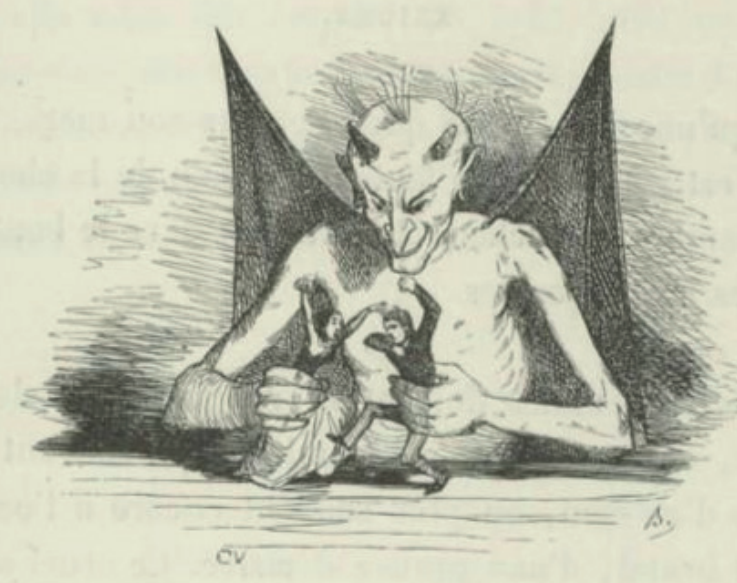

LA DERNIÉRE QUERELLE. 
medida defensiva, a qual pode vir sob forma

biomorfa exageradamente ampliada - assim como aparece no desenho de Bertall. Essas sensações são mais apuradas na infância, quando a fantasia tem um papel preponderante sobre o modo como enxergamos e interpretamos o mundo.

Mas esse não é 0 único episódio em que a doença e a iminência da morte afetam sua meninice. Desta vez é sua mãe que, em 1874, adoece gravemente em um resort em Ischl, na Áustria. Antes de se prostrar, Charlotte estava tão fraca que pediu para ser carregada em uma liteira durante a visita guiada ao Calvarienberg. A experiência com a doença e a proximidade da morte da mãe, em uma tenra idade, se fundem com os próprios passos da paixão de Cristo e marcam a associação entre as imagens da arte e o sofrimento físico. "Foi nesta ocasião que eu vi pela primeira vez (...) cenas da paixão de Cristo, cujo trágico e vulnerável poder silenciosamente pressenti”, conta Warburg (2004: 307).

As imagens também estão ligadas à objeção de A.W. aos planos familiares. Ele não apenas rejeita os rituais judaicos domésticos e o desejo materno de uma atuação religiosa (sua mãe projetava para ele o papel de rabino), mas também se indispõe contra as crenças judaicas. Se, por um lado, a carreira acadêmica não era exatamente 0 que uma família ortodoxa de banqueiros desejava para seu filho mais velho, por outro a atividade intelectual era uma tradição honrosa neste ciclo - Adolf Goldsmidt e Max J. Friedländer, respectivamente, filhos de famílias de banqueiros judeus de Hamburgo e de Berlim, decidiram-se pelo estudo da história da arte na mesma época de A. W. 0 problema, diz Gombrich (1970), era o tema de predileção de Warburg no estudo da arte: imagens. Especialmente, imagens cristãs e imagens do paganismo.

Figura 2: Sandro Botticelli, 0 Nascimento da Vênus (1483-85). Têmpera sobre tela

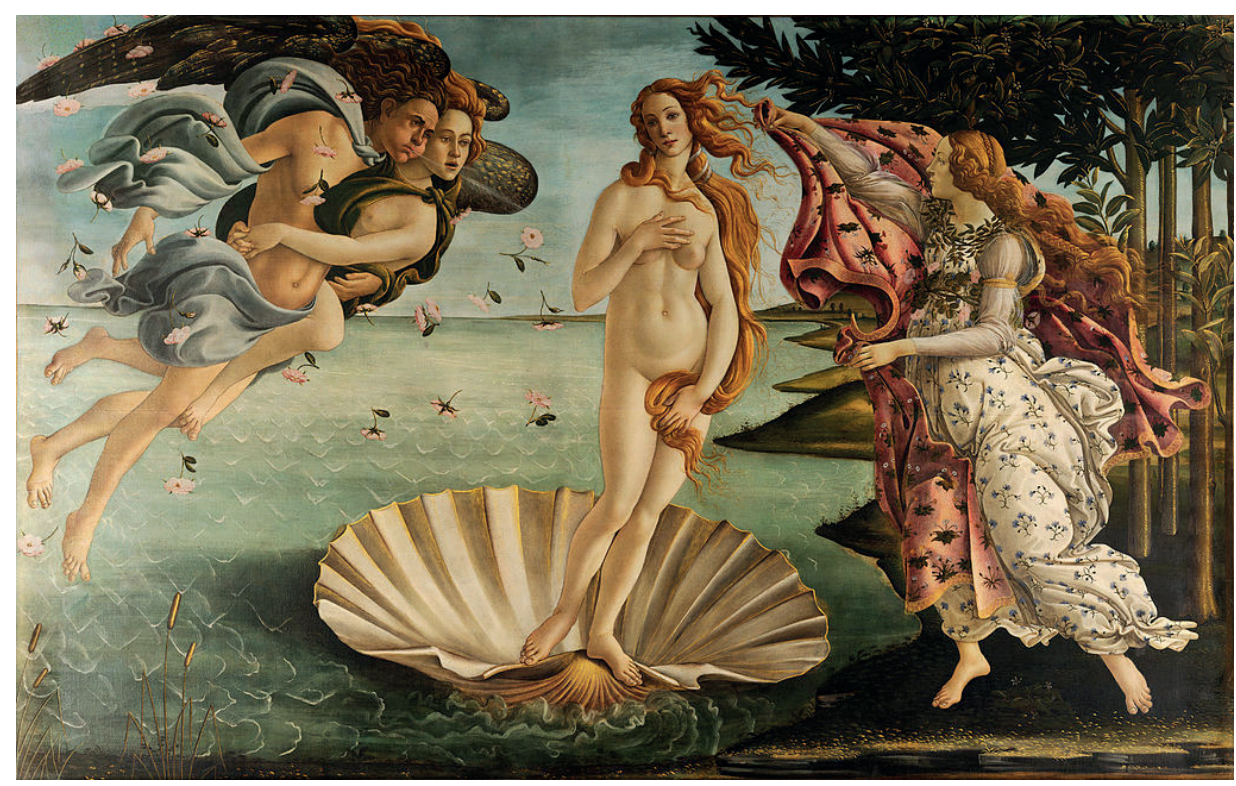


São muitas as implicações entre vida e obra de A. W.. Gombrich (1970) e Joseph Leo Koerner (2003), professor de História da Arte da University College de Londres, dizem estar convencidos da relação entre a sua forma de trabalhar, de produzir e de enxergar os fenômenos do mundo e suas experiências com seu sofrimento mental. A. W., que conseguia explicar o caráter irracional das imagens por ter ele mesmo experimentado a perda da razão, se valeria delas como instrumento terapêutico. Imagens aparentemente irracionais e sem sentido, cuja explicação concorria para que ele enxergasse a si mesmo nesses objetos experimentando o duplo sentido de refletir, de reflexão, atividades que combinam o espelho e 0 pensamento. Em determinado momento de sua análise, Warburg se perguntaria - de maneira bastante autorreferente, uma vez que ele receberá o diagnóstico de esquizofrênico ${ }^{7}$ - se os Pueblos, tribos que vivem no oeste dos Estados Unidos, entre o Arizona e o Novo México, eram realmente esquizoides e se isso equivaleria a viver em um estado misto, entre o delírio e a razão. Em nota datada do dia 3 de abril de 1929 e encontrada algumas semanas depois de sua morte, Warburg escreve que, como psico-historicista, se interessa pelos elos entre as imagens e a esquizofrenia da civilização ocidental e que o faz como reflexo autobiográfico (WARBURG, 2003; WARBURG \& BINSWANGER, 2007).

\section{Desesperadas confissões}

Após ameaçar sua própria esposa e filhos com uma pistola, Aby Warburg é internado em uma clínica em Hamburgo. Seu adoecimento coincide com os eventos do final do ano de 1918, nas semanas que se seguiam à derrota militar da Alemanha e alguns dias antes da renúncia de Guilherme II. Defensor do império alemão, A.W. começa a acreditar que ele e sua família estariam enredados em tramas persecutórias, envolvendo prisões secretas, torturas e assassinatos e que caberia a si arranjar uma forma para que sua família não caísse nas mãos de inimigos. Esses "inimigos" tanto poderiam ser os bolcheviques, determinados a matar intelectuais e capitalistas como eles; ou mesmo inimigos não concretos (KOERNER, 2003), como castigos divinos por ele ter abandonado o judaísmo - lembrando que o seu casamento com Mary Hertz, que vinha de uma família luterana, e a decisão de não circuncisar seus filhos e de não participar de rituais judaicos são atos duramente rechaçados pelos seus familiares. A. W. também imaginava que torturadores antissemitas, interessados em eliminar judeus influentes, poderiam estar atrás deles. Neste caso, A.W. antevia, de algum modo, os ares do que viria a se realizar com 0 terceiro Reich, evento que ele mesmo não chegou a vivenciar, tendo em vista que morreu em 1929, quatro anos antes, portanto, da criação do Nationalsozialismus por Hitler. 
Mas os "fantasmas" combatidos pelos seus médicos não eram de todo etéreos. A história mostraria que a histeria de A.W. não se alicerçava totalmente em devaneios. Na época, mesmo não sendo o nazismo uma realidade confessa, já se articulavam muitas ações no sentido de sua consecução. Max, seu irmão que havia ficado responsável pelo M.M. Warburg \& Co., estava sob ameaça de terroristas da extrema-direita alemã. Em sua investigação The Warburgs: The Twentieth-Century Odyssey of a Remarkable Jewish Family, o jornalista e historiador Ron Chernow (apud Koerner) conta que o guardacostas que cuidava de Max 24 horas por dia era, na verdade, um espião nazista. A mesma organização assassinou, em 1922, Walther Rathenau, PrimeiroMinistro de Assuntos Estrangeiros, que era judeu e amigo próximo da família Warburg.

Transferido para a clínica Bellevue, Aby ficou sob os cuidados do Dr. Ludwig Binswanger, colega de
C. G. Jung em Zurique, e estudioso da psicanálise freudiana. 0 próprio Freud, interessado por um paciente cuja obra "penetrante" lhe chama a atenção, chega a trocar correspondências com Binswanger na intenção de pesquisar o seu caso. Bellevue é conhecida por oferecer um tratamento mais humanizado (e discreto) para pacientes que podiam pagar por isso. Entre os pacientes da clínica acometidos por estados nervosos, estavam a feminista Bertha Pappenheim (que ficou conhecida como Anna 0., primeira paciente de Freud), o dançarino Nijinsky e o pintor impressionista alemão Ernst Ludwig Kirchner, fundador do Die Brücke.

Quase cinco anos depois da primeira internação, quando já não há mais esperanças de uma recuperação - seu prognóstico era "durchaus ungünstig" (absolutamente desfavorável) (WARBURG; BINSWANGER, 2007) -, Aby convence seus médicos a lhe deixar proferir

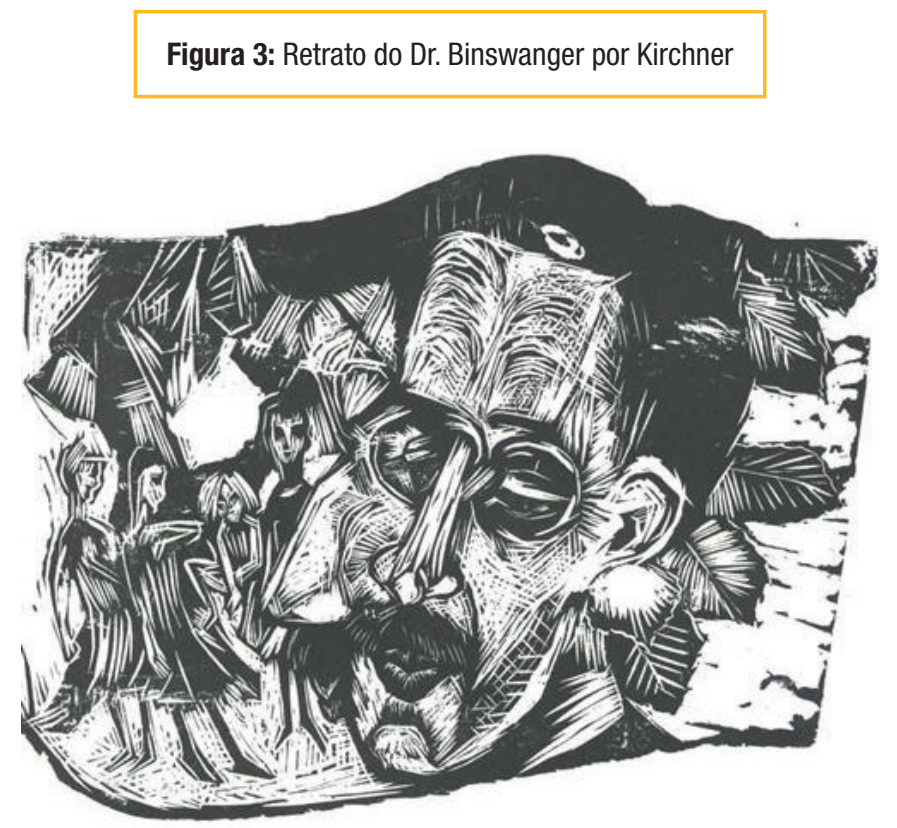


uma conferência como prova da recuperação de sua sanidade mental. Mais do que resultados (ele refuta o termo, que lhe soa como "um conhecimento científico supostamente superior"), Warburg fazia "desesperadas confissões". Confissões "de alguém em busca de redenção de um estado no qual sua tentativa de elevação espiritual havia sido aprisionada pela (e na) compulsão de se conectar através de uma incorporação real ou imaginária”. Ainda em suas palavras, "confissões de um incurável esquizoide" (WARBURG, 2004: 296).

Em Bellevue, o clima era de descrença e lamento. Embora se considerasse que sua excitação psicomotora esmaeceria pouco a pouco, não havia esperanças de que ele pudesse voltar às suas atividades científicas. Em carta de 8 de dezembro de 1921, Binswanger conta a Freud: "é verdadeiramente uma pena que ele não poderá extrair nada mais nem do tesouro do seu saber nem de sua imensa biblioteca" (WARBURG; BINSWANGER, 2007: 8).

Embora afundado em tormentos - ele acreditava que os gritos que ouvia nos corredores à noite eram ecos das torturas as quais a sua família estava sendo submetida, chegando mesmo a achar que a carne que lhe serviam no jantar era a de seus próprios filhos -, Warburg não opta por um tema "neutro" ou já devidamente explorado para sua conferência. Ao contrário, ele, que comparava Bellevue ao próprio inferno, realiza sua catábase se afundando em memórias ainda mais nebulosas, vivências de quase trinta anos, cujos significados permaneciam opacos para ele todo esse tempo. Aby volta ao ano de 1895, quando se depara com duas das fontes de angústia e medo mais ancestrais: 0 tema da serpente e dos fenômenos meteorológicos.

\section{Nachleben e Denkraum}

Em 1895, a bordo do navio Fürst Bismarck, Aby Warburg chega a Nova Iorque para 0 casamento do seu irmão Paul, que se realizaria no dia $1^{\circ} \mathrm{de}$ outubro daquele ano. Nos meses subsequentes, visita o Smithsonian Institution e entra em contato com importantes arqueólogos e estudiosos dos índios americanos ${ }^{8}-0$ que 0 encoraja a rumar a sudoeste e depois pela costa oeste, onde visita comunidades indígenas, faz fotografias e recolhe material ${ }^{9}$.

0 tema dessa viagem estava aparentemente encerrado. Após a experiência no oeste americano,

Em 3 de dezembro de 1895, Warburg conhece dois Navajos, que o impressionam enormemente. Do dia 14 de dezembro de 1895 a 30 de janeiro de 1986, Warburg visita comunidades situadas a leste do Rio Grande, como Santa Fé, San Juan, Acoma, Laguna, Cochiti e San Ildefonso, onde faz suas primeiras fotografias. Na costa oeste, visita Palo Alto e encontra Earl Barnes, um teórico que aplica o conto alemão Hans Guck-in-die-Luft na tentativa de compreender aspectos culturais do comportamento das crianças hopis. Em 7 de abril de 1896, visita a comunidade zuñis, no Novo México, e, em 21 de abril do mesmo ano, deixa a estação de Holbrook, no Arizona, final da ferrovia, e vence de charrete $150 \mathrm{~km}$ em dois dias para chegar em comunidades Hopis que viviam em Black Mesa, cadeia de planaltos montanhosos do Arizona. Com o reverendo, mercador e fotógrafo H. R. Voth, visita os Walpi e os Oraibi e, em 3 de maio de 1896, retorna para a Alemanha.

Anotações pessoais, objetos de culto e instrumentos ritualísticos coletados seriam depositados, em 1896, no Völkerkunde Museum de Hamburgo. 
A.W. profere três conferências em Berlim e

Hamburgo e retorna abruptamente para seus estudos sobre a Renascença italiana, parecendo ter concluído definitivamente suas pesquisas com os indígenas (MICHAUD, 2004). Contudo, em 17 de maio de 1907, em carta a James Mooney, etnógrafo americano e scholar do Smithsonian Institution, Warburg confessa que se sente devedor dos índios americanos pelo aprendizado que recebeu e que, sem 0 estudo de sua arte, ele jamais teria sido capaz de encontrar 0 acesso à psicologia primitiva. Em suas anotações, lê-se que as questões advindas dessa experiência lhe pesavam tanto na alma durante 0 tempo em que estava sadio que ele simplesmente não ousaria fazer, naquele momento, qualquer afirmação científica a respeito (WARBURG, 2004).

Vale lembrar que, embora seus estudos sobre a Renascença tenham lançado novas luzes sobre o tema, seu interesse não era pelo Renascimento em si, mas pela memória cultural e pelo que ele entendia como Nachleben, conceito idealizado por Anton Springer, mas que com Warburg ganha nova significaçã $0^{10}$. Warburg queria saber de que forma se dá a pós-vida, a sobrevida ou sobrevivência espectral das imagens primordiais e quais seriam os seus mecanismos de funcionamento.
Contrapondo-se aos estudos de sua época, os quais compreendiam o Renascimento como um período de rompimento com os valores da Idade Média, Warburg sustentava que o Renascimento florentino representava, sim, o início da modernidade, mas também o lugar de ressurgência de impulsos e memórias primitivos.

Leituras juvenis do Laokoon, de Lessing, haviam lhe incutido algumas questões que 0 acompanham por toda a vida, como o problema da expressão do sofrimento e sua contenção/repressão nos estados emocionais extremos, 0 excesso emocional que os antigos chamam de parenthyrsus. Para os seus contemporâneos, o pathos extremo dos gestos e dos movimentos violentos jamais poderia ser constituído na arte visual, precisamente porque, na hierarquia dos signos, a imagem era compreendida como algo estático que poderia apenas insinuar o movimento, mas não expressá-lo. Para o pensamento da época, a poesia, ao se desenrolar no tempo, seria capaz de descrever a transitoriedade e a mudança, enquanto os signos visuais se destinavam unicamente à representação do que está em repouso.

À medida que avançam seus estudos em Florença, especialmente quando ele se demora na observação das expressões faciais em obras

10 Além de se diferenciar de Springer (Rampley, 2000), o conceito de Nachleben der Antike, de Warburg, também se distancia das ideias de redespertar da Antiguidade, de J. Burckhardt, ou de imitação dos antigos, defendidas por J. J. Winckelmann. Segundo Gombrich (1970), o termo mais equivalente, na língua inglesa, não seria "after-life", mas "survival". Em um título que alude diretamente a essa dificuldade, G. Agamben, em Aby Warburg e la Scienza senza nome, afirma que o alemão Nachleben não quer dizer "renascimento" e nem "sobrevivência", mas "continuidade" - continuidade da herança pagã. Já em L'image survivante - Histoire de l'art et temps des fantômes selon Aby Warburg, Didi-Huberman (2002) traduz o termo como "sobrevivência". Sobre o tema, vale a pena consultar também o artigo de Felipe Charbel Teixeira, "Aby Warburg e a pós-vida das Pathosformeln antigas". As referências dessas obras encontram-se no final deste artigo. 
de Masolino e Masaccio na capela Brancacci, as questões suscitadas pelo Laokoon retornam. Além dos rostos, Warburg inquieta-se com os relevos dos arranjos ornamentais e decorativos, que, em sua opinião, nada tinham a ver com o estudo das aparências naturais. Esse tipo de afirmação dissente totalmente dos estudos de John Ruskin, eminente crítico de arte vitoriano, que declarava que 0 Quattrocento era marcado por uma devotada fidelidade, e de Winckelmann, que atribuía a esse tipo de escultura uma calm grandeur. Foi observando o farfalhar das vestes e dos véus pintados por artistas como Filippino Lippi e Sandro Botticelli que Warburg refutou a tese da imobilidade e da fidelidade. Mais do que se preocupar em retratar fielmente o mundo, esses artistas interpretavam estados anímicos turbulentos.

Em dezembro de 1891, Warburg termina sua tese sobre Botticelli e, em março do ano seguinte, muda-se para Berlim para cursar, por dois semestres, a faculdade de Medicina, onde assiste a aulas de Psicologia e se indispõe veementemente contra a Psicologia em voga no século XIX, cuja teoria dominante era o associacionismo, o qual entendia a mente como uma tábula rasa que recebia impressões através dos sentidos (GOMBRICH, 1970). Warburg definia-se como um psico-historiador, um sismógrafo da alma, situado entre o Ocidente e o Oriente, entre 0 paganismo primitivo e o renascimento católico (WARBURG, 2004). Mais do que pelas imagens da história da arte, ele estava interessado na dimensão antropológica de qualquer imagem (DIDI-HUBERMAN, 2002). A concepção puramente estética da história da arte lhe parecia uma tagarelice estéril e vazia (GOMBRICH, 1970).

As imagens, dotadas de um caráter demoníaco, formadas em profundezas abissais da consciência, ligadas a emoções que despertam reações fóbicas, traumáticas, se inscrevem na mente e na cultura. A esquizofrenia da cultura ocidental estaria exatamente em sua dificuldade de lidar com os conflitos que estão em sua base de formação imagética, em nossa falência para conciliar o logos e o pathos, a emoção primitiva e a reflexão, a representação racional e a representação mágica e poética da vida.

Figura 4: Painéis do projeto Atlas Mnemosyne. Instituto Warburg

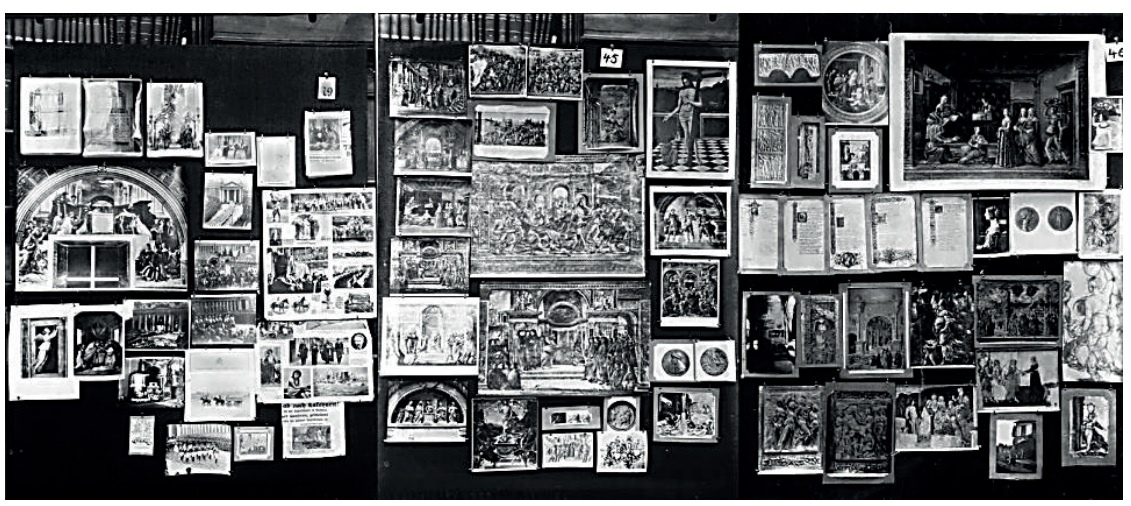


Opondo-se ao historicismo, que entendia a cultura como progresso, Warburg dizia que a cultura atuava como um jogo de forças permanente entre o pensamento racional e o mágico religioso, ou, usando termos nietzschianos, entre 0 apolíneo e 0 dionisíaco. Para não sucumbir ao mito e à imaginação poética, a civilização cria um movimento dialético que promove uma distância (abstração) entre 0 indivíduo e o objeto, entre $0 \mathrm{eu}$ e o mundo exterior. Essa distância como "espaço do pensamento", Denkraum, a qual contribui para a reflexão e a crítica, capaz de separar o homem de suas paixões, é perigosa. 0 perigo não é o da civilização sucumbir ao mito e ao trágico, mas 0 de se enredar em uma esterilidade esvaziada de sentido e de produzir símbolos rarefeitos.

\section{A serpente: veneno e cura}

De um indígena chamado Cleo Jurino, guardião da estufa (kiwa - como é chamado o santuário subterrâneo onde ficam depositadas as serpentes que atuarão no ritual), e seu filho Anacleto, Warburg recebe, em seu hotel em Santa Fé, desenhos com rascunhos de suas visões cosmológicas do mundo. Nesses, a serpente é representada como uma divindade meteorológica. Exceto pelas plumas, ausentes no desenho, a serpente era a mesma que Warburg havia visto em vasos de cerâmica, com uma língua em forma de flecha, e, posteriormente, nos muros de uma igreja de Laguna. Nesses desenhos, há uma semelhança entre a serpente e o raio - indicando sua atuação no ritual de dança que acontece em agosto, quando é aguardada a chegada das tempestades.

0 relâmpago e a serpente representam perigo; além disso, ambos têm um movimento enigmático e, em ambos, início e fim são de difícil precisão.

Figura 5: Desenho de Cleo Jurino figurando a serpenterelâmpago portadora da chuva. Hotel Santa Fé, 10 de janeiro de 1896

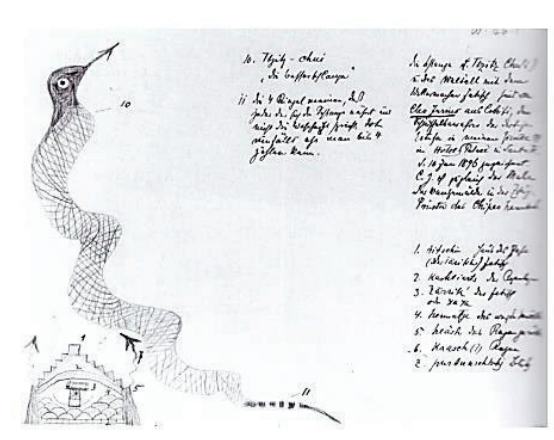

Caçadores e agricultores, os Pueblos vivem sob o regime matrilinear. Eles buscam a causa de sua existência na Mater certa, diz Warburg (2004), referindo-se à expressão latina "Mater semper certa est", princípio do direito romano que presume a certeza da maternidade e não da paternidade. Ligados ao mundo animal pelo totemismo, os Pueblos creem que a serpente é seu ancestral mítico.

Mas que qualidades teria a serpente para desempenhar esse papel? Warburg elenca cinco: a de perfazer um ciclo de vida que vai do sono mais profundo (morte) à mais intensa e potente forma de vida; a de se desfazer de sua pele e continuar sendo o mesmo ser; a de se deslocar rapidamente, embora não se pondo em pé, e a de apresentar visibilidade mínima (garantida pela lei do mimetismo e por viver escondida em pedras e 
buracos na terra). Quanto à quinta característica, Warburg escreve apenas: "Phallus". A serpente é essencialmente ambígua, por isso ela é Zrwãn, símbolo da eternidade.

\section{Figura 6: Aby Warburg com um dançarino hopi,} Oraibi, 1896

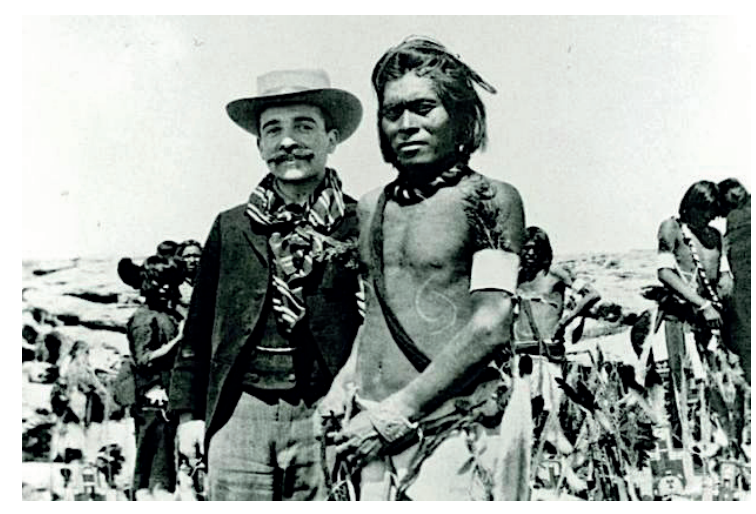

Em Oraibi e Walpi, uma das tribos Pueblos que ficam no território Hopi, entre os índios Moquis ou Mokis (como também são chamados os Hopis), realizava um ritual de dança em que uma das serpentes era eleita uma deidade meteorológica ${ }^{11}$. No $14^{\circ}$ dia dos festejos, três homens retiram do kiwa com as mãos desprotegidas serpentes venenosas previamente capturadas no deserto para 0 ritual e que estavam sob a proteção dos índios durante este período. Um deles prende a serpente em sua própria boca e começa a dançar com ela. A dança dura pouco mais de meia hora.
A função da dança da serpente era induzi-la a invocar os raios que trarão a chuva, fonte de vida e de regeneração. 0 fato de os índios não quererem se parecer com a serpente, mas compreenderem seu papel como um ator a mais no ritual, um intercessor divino, é, aos olhos de Aby, um progresso. Além da não existência da mediação mimética - uma vez que 0 animal é integrado ao ritual em sua forma mais imediata -, também ao final da dança, não se efetua o rito sacrificial. Ao contrário, a serpente é liberada para que retorne ao deserto, onde seu espírito poderá, finalmente, retornar em forma de raios. Warburg compara esses índios ao povo judeu, que caminhava pelo deserto guiado por Moisés. 0 deserto e a necessidade de água têm um papel fundamental na gênese da religião, lembra Warburg (2004).

Para Aby, o ritual da serpente em si era um avanço cultural sobre a imersão mimética no mundo animal. No seu entendimento, os índios visitados não viviam em estado de selvageria, mas se situavam em um híbrido entre a lógica e a mágica. 0 fabuloso, em que se enraízam os jogos e as artes entre os índios, é um sintoma e uma prova desesperada de pôr ordem no caos e lutar contra ele, e não uma "rendição prazerosa ao fluxo das coisas" (WARBURG, 2004: 305).

Em Laguna e Acoma, Aby descobriu na decoração das cerâmicas e na arquitetura que as imagens da serpente equivaliam ao raio anunciador da chuva. Em San Ildefonso, ele assiste à dança do antílope, que ratificava cerimonialmente as imagens dos ornamentos. No final de sua estadia dos Estados Unidos, ele assiste às festas sazonais de kumiskatcina, ritos destinados a assegurar abundância na colheita. Segundo Koerner (2003), como Aby deixa Oraibi na primavera, logo após a temporada das danças kumiskatcinas, ele não chega a presenciar o ritual da serpente, que acontece apenas em agosto. Suas pesquisas se apoiam em fotografias. 
Nas notas e rascunhos que fazem parte da preparação de sua conferência, ele retoma os ensinamentos de Tito Vignoli e Hermann Usener sobre os reflexos fóbicos e o homem primitivo (GOMBRICH, 1970). Para eles, o homem primitivo é uma criança em um quarto escuro, envolto em um caos que ameaça sua sobrevivência. 0 reflexo fóbico estaria na gênese do mito e, finalmente, também seria responsável pelo nascimento da ciência. A mente, em estado de permanente alerta, toma uma posição defensiva contra 0 real, fantasiando-0, uma vez que mesmo a mais terrível fantasia lhe causa menos prejuízos do que o desconhecido e 0 incontrolável. A reação fóbica prepara o terreno para a domesticação do mundo, nomeando e, deste modo, conduzindo o ignoto para o domínio do pensamento articulado, sistemático, lógico. A projeção do reflexo fóbico estaria no limiar da nossa consciência, soleira da qual a humanidade nunca ultrapassou por completo.

0 homem das sociedades tradicionais, que vivencia o mundo miticamente, consegue chegar a esse lugar de sistematização ordenando e estabelecendo sequências fixas, criando a ideia de um universo estruturado que possibilitaria a emergência do pensamento científico. A história da civilização é a história da luta contra 0 monstro, contra o reflexo compulsivo, motivo da projeção. 0 medo tragicamente enraizado em nossas mentes pode ser sublimado. A espiritualização do homem primitivo, para Warburg, seria uma tentativa de salvação. Assim, a serpente, ao assumir a forma do raio, dá aos indígenas o poder de controlar uma das mais temíveis forças da natureza. Ele compara as danças da serpente à conquista do domínio do homem civilizado em controlar a eletricidade.

Embora essa conferência seja para Warburg um motivo de libertação, uma espécie de atestado da integridade de suas faculdades mentais, e de encontro com seu passado no oeste americano e com suas leituras juvenis sobre o mito, Warburg demonstra certo pessimismo em suas deduções, provavelmente reflexo dos seus sofrimentos com a doença e a internação. Em suas palavras:

Aquele que superou o culto à serpente e o medo
do trovão, herdeiro dos autóctones e usurpador
dos índios em sua busca por ouro - só pude
fotografá-lo como símbolo numa rua em San
Francisco. (...) É o tio Sam, com sua cartola,
passando cheio de orgulho em frente a uma
rotunda imitada dos antigos. Sobre sua carto-
la vemos a fiação elétrica. É dessa serpente de
cobre edisoniana que ele arrancou o relâmpago
da natureza (...) 0 que colocar no seu lugar? As
forças da natureza não são mais concebidas
como forma antropomórfica ou biomórfica, mas
como infinitas ondas obedecendo à pressão da
mão humana. Deste modo, o que a civilização
da natureza, nascida do mito, penosamente
construiu, o espaço da contemplação (Anda-
chtsraum) se tornou o espaço do pensamento
(Denkraum). (WARBURG, 2003: 133 ).

Para ele, a maestria tecnológica que alcançamos sobre as forças da natureza, especialmente sobre a eletricidade, pode ser perigosa. A serpente de cobre, como ele chama os fios de Thomas Edison, encapsulou os relâmpagos da natureza. Em suas notas (WARBURG, 2003), Warburg diz que o moderno Prometeu e o moderno Ícaro, em 


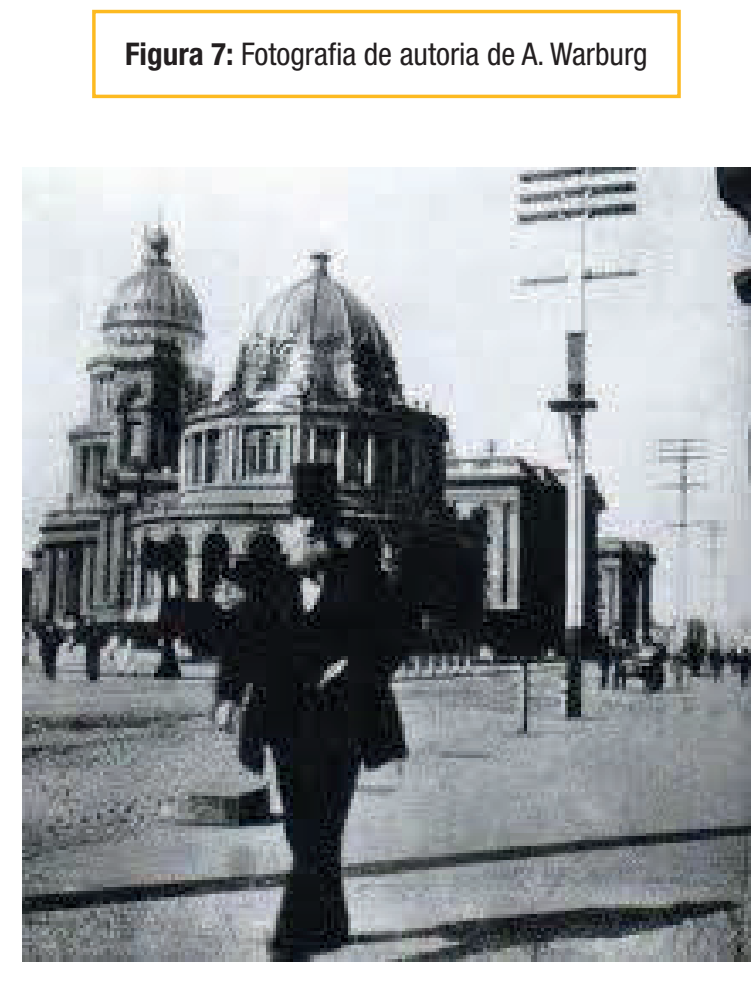

referência a Benjamin Franklin e aos irmãos Wright, são os fatídicos destruidores do senso de distância que ameaça levar o mundo de volta ao caos.

\section{A paixão segundo A.W.}

0 senso comum enxerga a paixão como desvio da racionalidade, uma fonte de prazer ou de angústia, de alegria ou de tristeza, de excitação ou de melancolia - mas nunca uma fonte de conhecimento válida ou aceita ou uma forma de articulação do pensar. 0 pensamento que se propõe lúcido se constitui como oposição ao pensamento apaixonado. A paixão cega. Pensar livremente é pensar desapaixonadamente. A paixão amordaça. 0 pensamento coerente compreende as regularidades e simetrias, enquanto que a paixão experiencia indistintamente. Ao ser apaixonado, não interessam distinções, fronteiras. Seus sentidos estão empapados de totalidade, de mônada, de presentidade. Paixão é acidente, imprevisibilidade e furor. Ligada aos impulsos, ao inconsciente, à irracionalidade, a paixão, como uma forma de afecção da alma, é condenável. A paixão deprava e degrada.

Ao comparar a condição de seus escritos, de suas reflexões, aos movimentos agônicos, ao sofrimento (pathos), da rã decapitada, Warburg desafia os estudos do seu tempo, rompe com esquemas predeterminados. 0 que ele inaugura não é uma nova história da arte, mas um novo olhar. Um olhar que se alicerça profundamente no ato de ver o que está imediatamente diante dos olhos - e para além e aquém deles.

A proposta de considerar o movimento e 0 pathos de Warburg não é apenas uma proposta metodológica para questões ligadas à análise da imagem ou à história da arte. Entender a paixão como uma forma de conhecimento significa promover um rompimento com modelos estéticos e epistemológicos - e com suas implicações políticas e sociais - totalizantes. Modelos que estigmatizam (e adoecem) o sujeito da paixão. 0 que Warburg nos ensina é a enfiarmos as mãos desnudas no buraco, kiwa, onde moram as serpentes e dançarmos com elas em nossas bocas.

\section{Referências}

AGAMBEN, G.. Aby Warburg e la Scienza Senza Nome. Disponível em: < http://www.scribd.com/ doc/82130092/Agamben-Aby-Warburg-E-La-ScienzaSenza-Nome > . Acesso em: 01/01/2015. 
BELTING, Hans. Antropología de la imagen.

Barcelona: Katz, 2007.

DARWIN, Charles. The expression of the emotions in man and animals. 1872. Disponível em: http://darwinonline.org.uk/contents.html\#books. Acesso em: 01/02/2014.

DETIENNE, Marcel. Dioniso a céu aberto. Rio de Janeiro: Jorge Zahar Ed., 1986.

DIDI-HUBERMAN, G. Limage survivante - histoire de l'art et temps des fantômes selon Aby Warburg. Paris: Les Éditions du Minuit, 2002.

GOMBRICH, E. A lifelong interest - conversations on Art and Science with Didier Eribon. Londres: Thames \& Hudson, 1993.

GOMBRICH, E. H. Aby Warburg: an intellectual biography. London: The Warburg Institute University of London, 1970.

GUERREIR0, Antonio. As imagens sem memória e a esterilização da cultura. Disponível em: < http:// www.porta33.com/eventos/content_eventos/Antonio_ Guerreiro_Aby_Warburg/Seminario_Antonio_Guerreiro. html > . Acesso em: 01/01/2015.

KOERNER, J. L. Introduction. Em: WARBURG, A. Le rituel du serpente - art \& anthropologie. Paris: Ed. Macula, 2003.

LEVINE, E. Dreamland of humanists - Warburg, Cassirer, Panofsky and the Hamburg School. Chicago: The University of Chicago Press, 2013.

MICHAUD, Philippe-Alain. Aby Warburg and the image in motion. Nova Iorque: Zone Books, 2004.

RAMPLEY, Matthew. From serpent ritual to cosmic allegory. Em: The remembrance of things past: on Aby M. Warburg and Walter Benjamin. TEIXEIRA, Felipe Charbel. Aby Warburg e a pós-vida das Pathosformeln antigas. Disponível em: < http:// www.historiadahistoriografia.com.br/revista/article/ view/171 >. Acesso em: 1 jan. 2015.
TRÍAS, Eugenio. Tratado de la Pasión. Barcelona: DeBOLS!LLO, 2006.

WARBURG, A. Essais Florentins. Klincksieck, 2003. . Le rituel du serpente - art \&

anthropologie. Paris: Ed. Macula, 2003. . Memories of a Journey through the Pueblo region. (apêndix 3, p. 293-336) Em: MICHAUD, Philippe-Alain. Aby Warburg and the image in motion. Nova Iorque: Zone Books, 2004.

. The Renewal of Pagan Antiquity. Los Angeles: Getty Research Institute, 1999.

WARBURG, A.; BINSWANGER, L. La guérison infinie histoire clinique d'Aby Warburg. Paris: Bibliothèque Rivages, 2007. 
PASSION ACCORDING TO AW notes on the ritual of the serpent and pathosformeln in Aby Warburg's thought

\section{Abstract}

In 1905, Aby Warburg formulated a concept that he would call Pathosformeln - a neologism created by him in his studies on Albrecht Dürer, but which was already present, in an inchoate way, in his first writings. Pathosformeln comes to psychic forces present in the collective memory in spectral forms, images featured by intense primeval energy. If the story of the Western thought contributes to the expulsion of the passion (pathos) from the logical and scientific domain - passion blurs and disrupts what has the intention to be lucid and clear - the legacy and the life of A.W. are testimonies of the undeniable effects of the passion to science.

However, before sophisticating the thesis that would change everything that had been said about Renaissance, personal experiences - such as his confinement to a nursing home and the contact with American West tribes - contributed to his insights on Florentine art.

\section{Keywords}

Pathosformeln. Image. Ritual. Art. Science.

\section{La pasión según A.W. - notas sobre el} ritual de la serpiente y las pathosformeln en el pensamiento de Aby Warburg

\section{Resumen}

En 1905, Aby Warburg formuló lo que llamaría Pathosformeln - neologismo creado por él en su estudio sobre Albrecht Dürer, pero que ya aparecía de forma rudimentaria en sus primeros escritos. Las Pathosformeln dicen respecto a las fuerzas psíquicas presentes en la memoria colectiva en formas espectrales, imágenes dotadas de intensa energía primitiva. Si la historia del pensamiento en el Occidente concurre para la expulsión de la pasión del dominio de la lógica y de la ciencia - la pasión estorba y embota lo que se pretende lúcido y positivo -, el legado y la vida de A. W. son testigos de los innegables efectos de las pasiones para las descubiertas científicas. Antes, sin embargo de sofisticar la tesis que redimensionaría todo lo que ya se había dicho sobre el Renacimiento, experiencias de carácter personal como su internación en un manicomio y el contacto con indígenas del oeste americano - contribuyeron para sus insights sobre el arte florentina.

\section{Palabras clave}

Pathosformeln. Imagen. Ritual. Arte. Ciencia. 


\section{Expediente}

A revista E-Compós é a publicação científica em formato eletrônico da Associação Nacional dos Programas de Pós-Graduação em Comunicação (Compós). Lançada em 2004, tem como principal finalidade difundir a produção acadêmica de pesquisadores da área de Comunicação, inseridos em instituições do Brasil e do exterior.

\section{E-COMPÓS I www.e-compos.org.br I E-ISSN 1808-2599}

Revista da Associação Nacional dos Programas de Pós-Graduação em Comunicação.

Brasília, v.18, n.3, set./dez. 2015.

A identificação das edições, a partir de 2008, passa a ser volume anual com três números.

Indexada por Latindex I www.latindex.unam.mx

\section{CONSELHO EDITORIAL}

Alexandre Farbiarz, Universidade Federal Fluminense, Brasil Alexandre Rocha da Silva, Universidade Federal do Rio Grande do Sul, Brasil Ana Carolina Damboriarena Escosteguy, Pontifícia Universidade Católica do Rio Grande do Sul, Brasil

Ana Carolina Rocha Pessôa Temer, Universidade Federal de Goiás, Brasil Ana Regina Barros Rego Leal, Universidade Federal do Piauí, Brasil Andrea França, Pontifícia Universidade Católica do Rio de Janeiro, Brasil André Luiz Martins Lemos, Universidade Federal da Bahia, Brasil Antonio Carlos Hohlfeldt, Pontifícia Universidade Católica do Rio Grande do Sul, Brasil

Arthur Ituassu, Pontifícia Universidade Católica do Rio de Janeiro, Brasil Álvaro Larangeira, Universidade Tuiuti do Paraná, Brasil Ângela Freire Prysthon, Universidade Federal de Pernambuco, Brasil César Geraldo Guimarães, Universidade Federal de Minas Gerais, Brasil Cláudio Novaes Pinto Coelho, Faculdade Cásper Líbero, Brasil Daisi Irmgard Vogel, Universidade Federal de Santa Catarina, Brasil Denize Correa Araujo, Universidade Tuiuti do Paraná, Brasil Eduardo Antonio de Jesus, Pontifícia Universidade Católica de Minas Gerais, Brasil

Daniela Zanetti, Universidade Federal do Espirito Santo, Brasil Eduardo Vicente, Universidade de São Paulo, Brasil Elizabeth Moraes Gonçalves, Universidade Metodista de São Paulo, Brasil Erick Felinto de Oliveira, Universidade do Estado do Rio de Janeiro, Brasil Francisco Elinaldo Teixeira, Universidade Estadual de Campinas, Brasil Francisco Paulo Jamil Almeida Marques, Universidade Federal do Paraná, Brasil

Gabriela Reinaldo, Universidade Federal do Ceará, Brasil Goiamérico Felício Carneiro Santos, Universidade Federal de Goiás, Brasil Gustavo Daudt Fischer, Universidade do Vale do Rio dos Sinos, Brasil Herom Vargas, Universidade Municipal de São Caetano do Sul, Brasil Itania Maria Mota Gomes, Universidade Federal da Bahia, Brasil
Janice Caiafa, Universidade Federal do Rio de Janeiro, Brasil Jiani Adriana Bonin, Universidade do Vale do Rio dos Sinos, Brasil José Afonso da Silva Junior, Universidade Federal de Pernambuco, Brasil José Luiz Aidar Prado, Pontifícia Universidade Católica de São Paulo, Brasil Juçara Gorski Brittes, Universidade Federal de Ouro Preto, Brasil Kati Caetano, Universidade Tuiuti do Paraná, Brasil

Lilian Cristina Monteiro França, Universidade Federal de Sergipe, Brasil Liziane Soares Guazina, Universidade de Brasília, Brasil Luíza Mônica Assis da Silva, Universidade de Caxias do Sul, Brasil Luciana Miranda Costa, Universidade Federal do Pará, Brasil Malena Segura Contrera, Universidade Paulista, Brasil Maria Ogécia Drigo, Universidade de Sorocaba, Brasil Maria Ataide Malcher, Universidade Federal do Pará, Brasil Marcia Tondato, Escola Superior de Propaganda e Marketing, Brasil Marcel Vieira Barreto Silva, Universidade Federal da Paraíba, Brasil Maria Clotilde Perez Rodrigues, Universidade de São Paulo, Brasil Maria das Graças Pinto Coelho, Universidade Federal do Rio Grande do Norte, Brasil

Mauricio Ribeiro da Silva, Universidade Paulista, Brasil

Mauro de Souza Ventura, Universidade Estadual Paulista, Brasil Márcio Souza Gonçalves, Universidade do Estado do Rio de Janeiro, Brasil Micael Maiolino Herschmann, Universidade Federal do Rio de Janeiro, Brasil Mirna Feitoza Pereira, Universidade Federal do Amazonas, Brasil Nísia Martins Rosario, Universidade Federal do Rio Grande do Sul, Brasil Potiguara Mendes Silveira Jr, Universidade Federal de Juiz de Fora, Brasil Regiane Regina Ribeiro, Universidade Federal do Paraná, Brasil Rogério Ferraraz, Universidade Anhembi Morumbi, Brasil Rose Melo Rocha, Escola Superior de Propaganda e Marketing, Brasil Rozinaldo Antonio Miani, Universidade Estadual de Londrina, Brasil Sérgio Luiz Gadini, Universidade Estadual de Ponta Grossa, Brasil Simone Maria Andrade Pereira de Sá, Universidade Federal Fluminense, Brasil Veneza Mayora Ronsini, Universidade Federal de Santa Maria, Brasil Walmir Albuquerque Barbosa, Universidade Federal do Amazonas, Brasil

\section{COMISSÃO EDITORIAL}

Cristiane Freitas Gutfreind

Pontifícia Universidade Católica do Rio Grande do Sul, Brasil

Irene Machado

Universidade de São Paulo, Brasil

\section{CONSULTORES AD HOC}

Claudia Peixoto de Moura, Pontificia Universidade Católica do Rio Grande do Sul, Brasil Francisco Rüdiger, Pontifícia Universidade Católica do Rio Grande do Sul, Brasil Juremir Machado da Silva, Pontifícia Universidade Católica do Rio Grande do Sul, Brasil Maria Aparecida Baccega, Universidade de São Paulo, Brasil

Roberto Tietzmann, Pontifícia Universidade Católica do Rio Grande do Sul, Brasil

\section{EQUIPE TÉCNICA}

ASSISTENTE EDITORIAL I Márcio Zanetti Negrini

REVISÃO DE TEXTOS I Press Revisão

EDITORAÇÃO ELETRÔNICA I Roka Estúdio

CONTATO I revistaecompos@gmail.com
COMPÓS I www.compos.org.br

Associação Nacional dos Programas de Pós-Graduação em Comunicação

Presidente

Edson Fernando Dalmonte

Programa de Pós-Graduação em Comunicação

e Cultura Contemporânea - UFBA

edsondalmonte@uol.com.br

Vice-presidente

Cristiane Freitas Gutfreind

Programa de Pós-Graduação em Comunicação Social - PUC-RS cristianefreitas@pucrs.br

Secretário-Geral

Rogério Ferraraz

Programa de Pós-Graduação em Comunicação

Universidade Anhembi Morumbi

rogerioferraraz@anhembimorumbi.edu.br 